\title{
Cine y propaganda cultural: la revista Der Adler en español (1940-1944)
}

\section{Cinema and cultural propaganda: Der Adler magazine in Spanish (1940-1944)}

\author{
Víctor Fernández Blanco \\ Carlos Monasterio Escudero \\ Universidad de Oviedo
}

\section{Resumen}

Este trabajo ofrece un estudio de caso del uso de la cultura, y específicamente del cine, como herramienta de propaganda en periodos excepcionales como una situación bélica. En concreto, se analizan los contenidos cinematográficos y culturales de la versión española de la revista Der Adler, editada por el Ejército del Aire alemán durante la II Guerra Mundial, y se discute su posible influencia en la sociedad española y en la posición del régimen franquista ante el conflicto bélico. El régimen nazi atribuía al cine un doble objetivo propagandístico: ofrecer evasión a la población y exaltar el régimen nazi y ejército alemán y sus hechos de guerra. Teniendo en cuenta estas metas, se construye una tipología del cine alemán durante el III Reich y se catalogan todas las películas que aparecen en la colección de la revista que se conserva en la Biblioteca Nacional de España, publicada entre 1940 y 1944. De su análisis se concluye que estos filmes son fundamentalmente de carácter escapista y amparan una doble intención. Con carácter general, distraer a la población alemana de las dificultades cotidianas que imponía el conflicto. $Y$, especificamente para España, ofrecer una imagen de normalidad, riqueza y potencia cultural que contribuyese a acrecentar el prestigio de Alemania. Por último, la revista también ofrecía reportajes propagandísticos de las actividades de españoles comprometidos con el régimen nazi, especialmente actuaciones de la División Azul y la Escuadrilla Azul.

Palabras clave: propaganda, cine, guerra, franquismo, III Reich.

Clasificación JEL: Z1O.

\begin{abstract}
This paper offers a case study of the use of culture, and specifically film, as a propaganda tool in exceptional periods such as a war situation. Specifically, it analyses the cinematographic and cultural contents of the Spanish version of the magazine Der Adler, published by the German Air Force during World War II, and discusses its possible influence on Spanish society and on the position of the Franco regime in the armed conflict. The Nazi regime attributed to cinema a double propagandistic objective: to offer evasion to the population and to exalt the Nazi regime as well as the German army and their acts of war. Taking these goals into account, a typology of German cinema is constructed during the Third Reich and all the films that appear in the collection of the magazine preserved in the National Library of Spain, published between 1940 and 1944, are catalogued. From their analysis, it can be concluded that these films are fundamentally escapist
\end{abstract}


in nature and serve a dual purpose. In general, to distract the German population from the daily difficulties imposed by the conflict. And, specifically for Spain, to offer an image of normality, wealth and cultural power that would contribute to increasing Germany's prestige. Finally, the magazine also offered propaganda reports on the activities of Spaniards committed to the Nazi regime, especially performances by the Blue Division and the Blue Squadron.

Keywords: Propaganda, cinema, war, Franco regime, III Reich.

JEL classification: Z10.

\section{Introducción}

El análisis económico de las actividades e industrias culturales se mide normalmente en términos monetarios, bajo el supuesto de que las empresas y productores de bienes y servicios culturales maximizan sus ingresos y el rendimiento de sus inversiones, en un contexto de competencia en el mercado.

Sin embargo, los bienes culturales se producen en numerosas ocasiones en contextos de «no mercado», donde se alteran las condiciones normales de producción y el objetivo a maximizar.

Uno de estos casos de «no mercado» acontece en los períodos bélicos. Durante ellos, no sólo se ve alterada la oferta de bienes culturales, en el sentido de que se controlan y/o prohíben sus importaciones, sino también que el objetivo de la oferta controlada por el Sector Público (y, en buena medida, también la permitida a los agentes privados) no es tanto la maximización monetaria del beneficio, sino la adhesión a ciertos valores y la difusión de determinadas ideas, conectadas con los objetivos bélicos, para que la población mantenga una moral elevada y se sienta impelida a participar en el esfuerzo productivo nacional. La propaganda es una herramienta clave para alcanzar este objetivo. En principio, tiene como destinatario fundamental e inmediato la propia población, con el objeto de consolidar las ideas nacionales y el ánimo y el compromiso de los ciudadanos con los ideales del país. Pero también puede dirigirse al exterior, con la intención de generar el desánimo en los rivales, mantener la moral y el apoyo de los aliados y ayudar a convencer a los neutrales o a los indecisos de las ventajas, incluso la superioridad, de las ideas que sostienen al país en cuestión. Ciertamente, los contenidos culturales pueden ser un vehículo muy eficaz para satisfacer todas estas metas de la propaganda. Y, sin duda, la ideología nacional-socialista fue de los primeros en entender esta idea, embarcándose en el diseño de la totalidad de la vida cultural de una nación ${ }^{1}$.

Este trabajo versa precisamente sobre esta vertiente internacional de la propaganda en periodo bélico. Se estudia el caso de la versión española de la revista alemana Der Adler, órgano de información y propaganda del Ejército del Aire del III Reich (Luftwaffe), que comenzó a publicarse en el año 1940 y cuyo último número

${ }^{1}$ Al promulgar la Ley de Teatro en 1934, el Ministerio de Cultura y Propaganda del III Reich afirmaba que «las artes son para el Estado Nacional Socialista una tarea pública; no solo son de naturaleza estética sino también moral, y el interés público exige no solo su supervisión policial sino también su orientación» (citado en Welch, 2007, p. 32). 
corresponde al 30 de mayo de 1944. España cumplía con las características de dos de las posibles dianas de la propaganda exterior. Por un lado, desde el 12 de junio de 1940, oficialmente España fue un país no beligerante. Pero, por otro, eran bien conocidas sus afinidades con los regímenes nacionalsocialista en Alemania y fascista en Italia. En concreto, este artículo estudia las razones para la difusión en España de esta revista y, especialmente, sus contenidos de propaganda cinematográfica y cultural, así como sus probables objetivos.

El trabajo se organiza del siguiente modo: la segunda sección analiza la especial situación de España en el contexto de la II Guerra Mundial y las razones para que, desde el lado alemán, se propiciaran acciones de todo tipo, incluidas las culturales, para reforzar la posición del Eje, aumentar su prestigio y, en última instancia, crear una corriente de opinión favorable a la entrada en guerra al lado de Alemania e Italia. También se muestran las razones que justifican la intensificación de la propaganda alemana en el período 1942-1944, durante la vigencia del «Grosse Plan» de propaganda, cuando se editan la gran mayoría de los números de Der Adler en español. La sección tercera describe la naturaleza y contenidos de la revista, con especial atención a su versión española. La cuarta resume la situación del cine alemán durante el III Reich. La sección quinta contiene el núcleo central del trabajo. En ella se realiza, en primer lugar, un análisis de la propaganda cinematográfica en la revista, según tipo de películas, temática y relación con los objetivos propagandísticos bélicos. En segundo lugar, se utiliza un modelo económico para contrastar la hipótesis de que el declive bélico alemán está relacionado con un mayor contenido de noticias cinematográficas escapistas y de evasión.

El sexto apartado repasa otros tipos de noticias culturales aparecidas en la edición española de Der Adler, pues, además de los contenidos cinematográficos, también utilizó temas de ópera y teatro, visitas culturales a ciudades y actividades de recreo y deportivas. Cierra el trabajo un breve apartado de conclusiones.

\section{La peculiar situación de España en la II Guerra Mundial}

El caso español es uno de los más llamativos, entre los países europeos que no participaron efectivamente en la II Guerra Mundial. Si algo destaca en la posición española fue el estrecho nexo con las potencias del Eje, especialmente Alemania e Italia, mantenida a lo largo de casi todo el período bélico.

En primer lugar, el gobierno de Franco se definió a si mismo como «no beligerante», en vez de «neutral», siguiendo el ejemplo italiano ${ }^{2}$. Por la fuerte vinculación del gobierno español con los dos países que le habían ayudado de manera decisiva a ganar la guerra civil, mediante una cuantiosa ayuda en hombres y material (Alpert, 1996),

\footnotetext{
2 Previamente al comienzo de la contienda mundial, España se había declarado neutral, según decreto publicado en el Boletín Oficial del Estado el 4 de septiembre de 1939. La entrada de Italia en guerra el día 10 de junio de 1940 parece haber sido la excusa para el cambio oficial de posición del régimen franquista.
} 
al principio de la contienda parecía que España se mantenía en un compás de espera, aguardando el momento oportuno para entrar en guerra, al lado de Alemania e Italia.

En segundo lugar, desde España se reclutaron y enviaron tropas que pelearon en el bando alemán, en el escenario del frente ruso. Este es el caso de la llamada «División Azul», división española de voluntarios, con una mayoría de falangistas entre sus filas. Sin embargo, para evitar una participación directa en el conflicto, estas tropas estaban integradas dentro del ejército alemán, formando la $250^{\mathrm{a}}$ División de Infantería, habiendo prestado juramento de fidelidad al Fhürer y combatiendo bajo uniforme alemán. En palabras de su segundo comandante, el general Esteban Infantes,

Ya no vestía el uniforme nacional, con gran pesar suyo; pero el caqui estaba desterrado en el ejército alemán y por tener que combatir a su lado y en combinación con divisiones del Reich, el uniforme y distintivos tenían forzosamente que ser los empleados en Alemania... La División Azul ha salido para Rusia. Ya está convertida en una división de infantería alemana, con los mismos efectivos, las mismas armas, la misma organización, el mismo uniforme y la misma instrucción (Esteban Infantes, 1956, p. 26).

Este caso de la División Azul, y también el de la Escuadrilla Azul que combatió con la Luftwaffe en el frente ruso, refleja fielmente la postura mayoritaria del gobierno español: apoyo a Alemania, pero sin involucrarse formalmente en el conflicto, esperando la ocasión oportuna para participar en la contienda, sin que quedara duda acerca del lado del cual estaría, si fuera beligerante ${ }^{3}$.

Pero ni todas las fuerzas políticas que habían estado detrás del Alzamiento Nacional ni todos los ministros del gobierno compartían sin reservas este alineamiento. Existían causas internas y externas que cuestionaban esta postura mayoritaria.

En el seno del gobierno, había ministros que, recién acabada la guerra civil, pensaban que lo mejor para el país era permanecer al margen de la contienda mundial, solicitar créditos exteriores que facilitasen la reconstrucción de unas infraestructuras en ruina tras la guerra civil, disminuyendo paralelamente el gasto militar, para posibilitar inversiones productivas (Larraz, 2006, pp. 240-247 y 256-268).

Aparte de quienes defendían la neutralidad española por convicción y para permitir la reconstrucción del país, estaban quienes lo hacían por interés, incentivados por los sobornos de países aliados, especialmente Gran Bretaña. Este era un hecho comentado ya en su momento. El 16 de junio de 1942, el ministro italiano de Asuntos Exteriores anotaba en su diario que, en una reunión con su homólogo español Serrano Súñer, este le contaba que Gran Bretaña gastaba diez millones de pesetas al mes en propaganda, para evitar la entrada en guerra de España al lado del Eje (Ciano, 2004, p. 649)4.

\footnotetext{
${ }^{3}$ Ros Agudo (2002) aporta un completo análisis de la postura española a este respecto.

${ }^{4}$ A propósito de este hecho, merece la pena anotar el agudo comentario del Rey de Italia, presente en la mencionada conversación, que restaba peligro al hecho debido a que «la experiencia enseña que de estos fondos reservados, buena parte se queda por el camino, en los bolsillos de los propagandistas y que a los “propagandados' [sic] no les llegan más que migajas».
} 
La reciente desclasificación de documentos británicos ha permitido conocer cómo funcionó esta estrategia (Viñas, 2016). Por un lado, se pagaron importantes sumas a destacados personajes militares, distribuidas a un primer círculo de personas influyentes a través del banquero Juan March. A partir de ahí, existían otros dos círculos de influencia que recibían los pagos del nivel anterior para evitar que la operación se difundiera.

Por otro, los británicos jugaron la baza de los navycerts, la autorización a los buques que traían suministros a España (especialmente, trigo argentino) para poder atravesar el bloqueo naval establecido por la Royal Navy. Así, la hábil actuación del embajador Hoare permitió contrapesar la fuerte influencia alemana ${ }^{5}$.

Respecto a las causas externas, la intervención militar efectiva de España exigía unos requisitos previos que no eran fáciles de aceptar por parte de sus aliados, especialmente Alemania.

Aunque la intervención española suponía neutralizar Gibraltar y crear una grave amenaza a Inglaterra en el Mediterráneo, las contrapartidas a satisfacer eran onerosas. Por un lado, habría que prestar ayuda alimenticia a España, devastada tras la guerra civil, y también ayuda militar para equipar a su ejército con material de combate moderno. Para un país en guerra, como Alemania, eso suponía distraer importantes recursos necesarios para su propio esfuerzo bélico.

Por otro, y seguramente más importante, la petición de contrapartidas territoriales por parte de Franco dirigidas a obtener parte de las colonias francesas en África, suponía para Alemania enemistarse con el gobierno colaboracionista francés de Vichy (Ciano, 2006, pp. 472 y 486; Trevor-Roper, 2004, p. 533).

Esta pugna soterrada de intereses dentro del gobierno español era conocida también por los altos círculos políticos alemanes. Es importante tener en cuenta lo que pensaban entonces los protagonistas de las decisiones, porque de acuerdo con esa percepción es como planteaban sus estrategias de propaganda e influencia en los países neutrales, como España.

Como ejemplo, en sus conversaciones privadas, Hitler comenta en diversas ocasiones su desconfianza respecto a Serrano Súñer, tanto por el nepotismo que observa en su nombramiento como, sobre todo, por considerarlo ligado a los intereses de la Iglesia y los conservadores monárquicos. En definitiva, considera que está practicando un doble juego, engañando al Eje y favoreciendo una restauración monárquica. (Trevor-Roper, 2004, pp. 107, 416, 453-455 y 556)

Como alternativa, Hitler considera necesario reforzar el peso político de Falange, fuerza más afín a Alemania, y trata de favorecer esta opción promoviendo la popularidad del general Muñoz Grandes (primer comandante de la División Azul) y recomendando sea recompensado con una alta condecoración en la primera ocasión posible, para reforzar su posición, por si en un momento dado llegara la hora de «derribar a ese régimen dirigido por curas» (Trevor-Roper. 2004, p. 486).

\footnotetext{
${ }^{5}$ Las memorias de Samuel Hoare, embajador en España entre junio de 1940 y el fin de la II Guerra Mundial, abundan en ejemplos de este uso de los «navycerts» para presionar al gobierno de Franco.
} 
A la hora de influir en la orientación política española, los aliados (especialmente Gran Bretaña) no podían incidir directamente sobre la opinión pública y debían conformarse con otorgar prebendas a miembros de la elite política y militar. Mientras, los países del Eje utilizaban ambas vías.

Para Alemania la propaganda era un asunto esencial dentro de la guerra. Así, cuando se designó al general von Faupel como primer embajador ante la España de Franco, por expreso deseo de Hitler se le proporcionó un grupo de especialistas en prensa, radio y, lo que es muy significativo para este ensayo, asuntos cinematográficos (Ros Agudo, 2002, pp. 272-273).

Teóricamente, en España la propaganda de los países beligerantes estaba prohibida por una temprana Orden del Ministerio de Gobernación, que disponía que «por las autoridades correspondientes, se procederá a la clausura de los locales en que, con el nombre de salón de lectura, biblioteca u otro similar, se realice propaganda de los países beligerantes por medios orales o escritos o facilitando libros, impresos, notas, folletos, documentos, etc.» (BOE, 1940, p. 4088).

Sin embargo, en la práctica esta era una declaración meramente retórica de «neutralidad legislativa», que nada tenía que ver con la conducta del régimen en cuanto a la difusión de propaganda en favor de uno u otro bando. La propaganda de los países del Eje circulaba profusamente y no era obstaculizada, frente a la prohibición de la favorable a los Aliados. Como explica en detalle Ramón Garriga, hasta 1942 la prensa española era intensamente pro alemana, gracias entre otras cosas a la influencia de Hans Lazar, agregado de prensa de la Embajada alemana, que además de sus importantes conexiones políticas al más alto nivel, distribuía fondos cuantiosos entre los periodistas españoles (Garriga, 1976, pp. 97-110, 290-291, 395, 401-402 y 421-423).

A medida que pasaba el tiempo y la guerra no se decidía a favor del Eje, Alemania consideró necesario intensificar y reorientar la influencia y la propaganda. Con este objetivo, el «Grosse Plan» de propaganda comenzó a operar en enero de 1942 y continuó hasta 1944, cuando la falta de presupuesto y de papel obligó a cesar la propaganda activa, incluyendo la difusión de publicaciones ${ }^{6}$. En España, aunque la posición oficial era cada vez más ambigua, la propaganda pasiva, gracias a la colaboración de numeroso personal del servicio de Correos, continuó hasta casi el final de la guerra, interceptando y destruyendo un gran número de publicaciones de propaganda aliada, incluso mediante el uso de la violencia física (Schulze Schneider, 1994, pp.375-381; Ros Agudo, 2002, pp. 290-298).

Es en medio de esta pugna de opiniones e intereses contrapuestos donde debe buscarse el sentido de la propaganda cultural nazi en España y, en particular, al caso de la revista Der Adler. Su edición española apareció en 1940 y coincidió plenamente con el período de vigencia del «Grosse Plan». Y su objetivo final era dibujar

${ }^{6}$ Entre las publicaciones de propaganda gestionadas por la propia embajada alemana, hallamos algunas de carácter oficial, como la revista juvenil Heroísmo y aventura, que narraba los combates del ejército alemán, a otras de carácter más o menos irregular o clandestino, como la satírica Coleccción de los 7, de la que llegaron a editarse 300.000 ejemplares (Irujo, 2012). 
un mundo atractivo y próspero, en lo material y en lo cultural, al que España podía pertenecer, si se decidía a participar en la guerra al lado de Alemania y sus aliados.

\section{Der Adler: Características y contenidos}

\subsection{Características generales}

Las tres armas del ejército alemán publicaron revistas propagandísticas destinadas a ensalzar la naturaleza y los hechos de cada una de ellas y a difundir, en el interior y el exterior, la política militar y, del III Reich. Die Kriegsmarine y Die Wehrmacht eran las revistas de la Marina y el Ejército de Tierra y Der Adler la del Ejército del Aire (Luftwaffe) 7 . Aunque las dos primeras aparecieron en 1935 y 1936, respectivamente, Der Adler hubo de esperar hasta marzo de 1939 (ABC, 2014; Leclercq, s.d.). Este retraso se atribuye a la prohibición de disponer de una aviación de carácter militar que los vencedores de la Primera Guerra Mundial impusieron a Alemania. En total, vieron la luz más de 140 números, con periodicidad quincenal, en el periodo comprendido entre finales de febrero de 1939 y septiembre de 1944.

A partir de 1940, fueron apareciendo ediciones en francés, inglés, español e italiano. Por su contenido y orientación propagandística, la edición en inglés se destinó fundamentalmente a los Estados Unidos. Algunos números especiales se publicaron también en otros idiomas de países conquistados o afines (húngaro, esloveno, finlandés, rumano, croata, sueco), pero sin llegar a una edición continuada de la revista. A lo largo de 1944, las ediciones extranjeras dejaron de publicarse y la versión en alemán lanzó su último número en septiembre de 1944. Las ediciones alemana e internacionales compartían una misma estructura y buena parte de los contenidos, especialmente aquellos dedicados a exaltar la Luftwaffe o la información general. Pero hay alteraciones ocasionales, incluso en la portada, para destacar algún aspecto que afecta a cada uno de los países en particular.

La edición española, que se distribuía para España y Portugal, comenzó en el número 14 del año 1940 y concluyó con el número 13 del año 1944. Hasta el número 11 de 1941, la publicación combinaba alemán y castellano Para su estudio hemos acudido a la colección conservada en la Biblioteca Nacional de España. A pesar de ser la recopilación más completa disponible de la versión en español de la revista alemana, hay algunas lagunas en su listado de números. En concreto, no se ha podido acceder a los números 10,12 y 13 del año 1944. En definitiva, hemos tenido acceso a 101 números de la revista ${ }^{8}$.

${ }^{7}$ Desde 1940 y hasta comienzos de 1945, el Ejército de Tierra pública también Signal, una revista de propaganda del régimen y el ejército alemán difundida solo en el exterior.

${ }_{8}$ También nos hemos ayudado de una selección de ejemplares procedentes de la colección particular de uno de los autores y de los disponibles en https://archive.org/search.php?query=der\%20adler\%20 espa\%C3\%B1ol\&and[]=loans__status__status\%3A\%22NULL\%22) 


\subsection{Contenidos}

Der Adler es esencialmente una revista propagandística cuya columna vertebral es difundir las virtudes del Ejército del Aire alemán y de otros servicios asociados como la defensa antiaérea o el cuerpo de paracaidistas. Con carácter general, la calidad de la revista, el tono general de victorias militares y el prestigio económico y cultural que transmite debía difundir una imagen de prosperidad envidiable del posible aliado. Combina artículos de propaganda con otros de divulgación destinados a explicar los principios esenciales, las novedades tecnológicas y los rasgos y la práctica de la aviación. Es frecuente el relato de las batallas aéreas y hazañas de los aviadores, muchas descritas en forma de relato casi novelístico y con un notable apoyo gráfico. En ocasiones, el texto vaya acompañado por reportajes fotográficos que ilustran el éxito de las misiones aéreas. También menudean los artículos que describen la vida cotidiana de aviadores, técnicos y soldados del Ejército del Aire, normalmente con un carácter distendido y reflejando sus horas de ocio y de formación ${ }^{9}$. En su edición española aparecen periódicamente noticias acerca de la heroica actuación de los aviadores españoles y los soldados de la División Azul, fortaleciendo la imagen del grupo político español más afín a la intervención al lado de Alemania.

La actividad propagandística también debía extenderse a la descripción de los aspectos cotidianos que, si bien en los primeros números eran una descripción casi idílica de la vida en Alemania, con el transcurso de la guerra fue dando paso a la descripción de la conducta heroica de los ciudadanos, por ejemplo, ante los bombardeos aliados sobre las ciudades germanas. Conscientes, tal y como sostenía Goebbels, del poder de la cultura como arma de propaganda, y de un modo sutil, pero no menos efectivo, los números de Der Adler están trufados de temas históricos comunes y noticias relacionadas con el mundo de la música, el arte, las artes escénicas o el deporte que, en el fondo, suponen un incentivo para adherirse a la causa del Eje. Pero, sin duda, quien acapara la mayor atención es el cine, con numerosos reportajes sobre el rodaje y los contenidos de diversas películas o incluso la promoción de algunas estrellas femeninas. En los contenidos propagandísticos de Der Adler priman las imágenes, las fotografías y los dibujos, dejando el predominio del texto para el caso de los artículos de divulgación científico-técnica y los relatos bélicos.

El estudio de la versión española de Der Adler permite ver cómo, manteniendo la misma filosofía general, la intensidad y el espacio destinado a cada tipo de noticias va cambiando con la suerte de la contienda. Los años 1940 y 1941 son los de mayor presencia de noticias bélicas y militares. Las referencias culturales son, en general, escasas y centradas sobre todo en actividades deportivas y musicales. Y lo mismo puede decirse de las cinematográficas: apenas se halla una noticia de ese cariz en el año 1940 y, en 1941, solo encontramos referencias es seis de los veintiséis números

\footnotetext{
${ }^{9}$ En los contenidos propagandísticos predomina la ilustración sobre los textos, en consonancia con la opinión de Hitler que, en Mein Kampf, apuntaba que «la propaganda gráfica... los individuos no son obligados a hacer ningún trabajo mental. Basta mirar los pequeños textos» (cit. en Da Costa, Ideología, 26).
} 
de ese año. Además, predominan los reportajes sobre películas bélicas, tanto en el ámbito de las obras de ficción como de los documentales.

En 1942 se inicia el cambio de ciclo. Las malas noticias en los distintos frentes (derrota de El Alamein, cerco de Stalingrado, desembarcos norteamericanos en el norte de África o el endurecimiento de las incursiones aéreas aliadas en suelo alemán) debieron influir en la línea editorial de Der Adler que, sin abandonar su naturaleza bélica y militar, dio cada vez más importancia y espacio a reportajes «civiles» que presentaban el lado amable de la vida alemana y concordaban con la opción escapista que se iba haciendo cada vez más mayoritaria en la propaganda cultural del III Reich. En este año, aparecen noticias culturales en dieciocho de los veintiséis números y cinematográficas en veintidós. Tras la derrota de Stalingrado, en febrero de 1943, el peso de la cultura y el cine se sostiene (los números con reportajes culturales y cinematográficos son veintidós y diecinueve, respectivamente), mientras cada vez ganan más espacio los reportajes geográficos, de costumbres, y vida más o menos normal, en pueblos y ciudades alemanas. Finalmente, los pocos números publicados en 1944 ahondan en dicha realidad. La propaganda cultural de naturaleza evasiva ocupa ya prácticamente un tercio de las páginas de la revista con una presencia cada vez más notoria de las crónicas paisajísticas y pintorescas

En todo caso, y por su calidad general, el fuerte contraste que suponía Der Adler respecto a la propaganda directa y burda del nacionalcatolicismo del régimen español, forzosamente tuvo que impresionar favorablemente a los lectores de mayor nivel cultural.

En suma, esta propaganda dibujaba en un mundo atractivo y próspero, en lo material y en lo cultural, al que España podía pertenecer, si se decidía a participar en la guerra al lado de Alemania y sus aliados.

\section{El cine alemán y el III Reich}

El objetivo de este apartado es analizar el papel desempeñado por en cine como vehículo propagandístico del régimen nazi. Parece oportuno comenzar describiendo las características generales de la industria cinematográfica bajo el III Reich. Como anticipo, se resume la situación previa del sector mediante dos grandes trazos: sus características en el periodo comprendido entre 1918, final de la Primera Guerra Mundial, y 1933, año del nombramiento de Adolf Hitler como Canciller; y la creación y el desarrollo de la productora de referencia Universum Film Aktiengesellschaft (UFA).

\subsection{El cine antes del III Reich}

Al finalizar la Primera Guerra Mundial, Hollywood dominaba los mercados europeos. Francia y Alemania respondieron apostando por un cine más artístico que 
alumbró diversos movimientos cinematográficos, como el dadaísmo, el surrealismo o el expresionismo.

En el comienzo de los años veinte, la industria cinematográfica alemana se fortaleció con el acceso a créditos en marcos más fáciles de devolver a su vencimiento merced a la devaluación. En este periodo, el cine fue muy fértil en estilos y contenidos. Buena parte de los productos perseguían conquistar al público con películas de evasión y gran espectáculo ${ }^{10}$. Fue el momento cumbre del «cine de montaña» (Bergfilm), pero también de las comedias musicales y de las adaptaciones de hechos históricos y clásicos de la literatura. El cine realista y social de Georg Wilhelm Pabst y el de lo cotidiano de la Kammerspiel ponían el contrapunto.

Los partidos políticos tampoco fueron ajenos a la efervescencia del cine. Desde sus comienzos, el Partido Nacionalsocialista lo concibió como una herramienta de propaganda y creó un departamento cinematográfico ya en 1930. Mientras, los partidos progresistas impulsaron sus producciones cinematográficas «militantes».

Pero, por encima de todo, destaca el movimiento expresionista. Fue una reacción contra el realismo, el naturalismo y el impresionismo, y una apuesta por una subjetividad distorsionada. Su periodo de vida fue corto: nacido con Das Cabinet der Dr. Caligari (Robert Wiene, 1920), a mediados de la década de 1920 su recorrido estaba prácticamente finalizado, aunque dejó profunda herencia en el cine alemán, en películas como Nosferatu, eine Symphonie des Grauens (F. W. Murnau, 1922) o Metropolis (Fritz Lang, 1927), y también en el Hollywood clásico.

En diciembre de 1917, el Alto Mando alemán creó la Universum Film Aktiengesellschaft (UFA) con intenciones propagandísticas y de educación/adoctrinamiento del pueblo. Se consolidó como el primer y más poderoso agente de la industria cinematográfica alemana mediante la adquisición o control de otras compañías cinematográficas (Kracauer, 1985, pp. 41-44; Kreimeier, pp. 29-33), y los procesos de integración vertical e internacionalización, especialmente en el ámbito de la exhibición (Gomery y Pafort-Overduin, 2011, p. 99). En 1921 fue privatizada, lo que hizo girar parcialmente sus objetivos propagandísticos hacia otros más comerciales.

Ayudada por la política proteccionista del gobierno alemán, que impuso cuotas a la importación de filmes norteamericanos, llegó a competir con el cine de Hollywood. Su producción combinaba noticiarios, películas comerciales y obras de contenido más artístico. En 1927, fue adquirida por Alfred Hugenberg, un personaje ligado a la empresa Krupp, y pasó a organizarse con criterios más mercantiles, que incluían acuerdos de exhibición, así como de importación y exportación, con grandes estudios de Hollywood, aunque esa alianza fue efímera.

A partir de 1933, la UFA pasó a ser un importante engranaje en el sistema de propaganda y control del cine dirigido por Joseph Goebbels, ministro de Pro-

\footnotetext{
${ }^{10}$ Elsaesser (1997, pp. 45-51) sostiene que esa diferenciación entre producción «popular»y «artística» era también una estrategia comercial para permitir al cine alemán competir en los mercados nacionales e internacionales.
} 
paganda, hasta acabar integrada en la práctica con las otras grandes compañías cinematográficas: Tobis, Terra y Bavaria.

\subsection{El cine en el Tercer Reich}

El 30 de enero de 1933 el presidente Hindenburg nombra canciller a Adolf Hitler. Muy pronto, el 13 de marzo de 1933, Hitler crea el Ministerio de Instrucción Pública y Propaganda (Reichsministerium für Volksaufklärungund Propaganda), que encarga a Joseph Goebbels. La gestión del cine se llevaba a través del Departamento de Cine que, con la ayuda de diversas instituciones, ejercía el control, la censura e incluso la prohibición de aquellas películas que no se ajustaban a la imagen del régimen, la regulación de las relaciones básicas de industria, desde la fijación del precio de las entradas o las condiciones de las salas de exhibición a las relaciones entre los agentes de la industria, y el comercio exterior y las relaciones internacionales. También controlaba a artistas, productores y empresarios cinematográficos. En este ambiente político e institucional, aunque los productores lograron cierta independencia animada esencialmente por criterios de rentabilidad económica, se produjo un éxodo muy importante, cuantitativa y cualitativamente, de trabajadores, técnicos, directores y artistas del cine alemán.

Esta emigración, la subida de los costes salariales y el progresivo boicot a la exportación de producciones alemanas, que entre 1933 y 1937 pasaron de representar del $43 \%$ al $7 \%$ de los ingresos del sector, embarcaron a la industria cinematográfica alemana en una profunda crisis económica que provocó el cierre de muchas pequeñas productoras y facilitó el proceso de concentración y estatalización del sector auspiciado por el régimen nazi. Así, en 1942, se completó la fusión de las grandes compañías (UFA, Terra, Tobis, Bavaria Film, Wien Film, Berlin Film) en «Ufi-Group» y la distribución se concentró en la división correspondiente de la UFA. En el sector de la exhibición, la cadena de salas de la UFA convivió con numerosas empresas de exhibición privadas, pero sometidas a una estrecha regulación y control.

La ideología nazi era muy consciente de la potencia del arte en general, y del cine en particular, como medios de propaganda y adoctrinamiento. En palabras de Goebbels, el cine era «uno de los medios más modernos para obrar sobre la masa ... [y una] posibilidad única de contribuir al trabajo de la formación política en el mejor sentido de la palabra» (citado en Hueso, 1998, p. 90).

En consecuencia, los objetivos fundamentales del cine eran suministrar escapismo y evasión a la población y, cuantitativamente en menor medida, convertirse en un vehículo de propaganda de las organizaciones y las políticas nazis ${ }^{11}$. Para diseminar esa influencia, el régimen lo difundía en instalaciones militares y factorías y en zonas

11 De las más de mil producciones realizadas durante el régimen nazi, apenas un $10 \%$ pueden considerarse esencialmente propagandísticas (Hake, 2008, p. 73). Al inicio del conflicto bélico este porcentaje aumentó para volver a disminuir tras la derrota de Stalingrado, en febrero de 1943. 
rurales y pequeñas localidades, es este caso mediante una flota de 300 camiones y dos trenes que transportaban todo lo necesario para exhibir películas, También desarrolló un «star system», depurado de estrellas de origen judío, que ofreciese una imagen positiva del nuevo régimen y respondiese al ideal de belleza alemana.

Desde el punto de vista financiero, la primera medida de política cinematográfica fue la creación de un banco que concedía créditos a bajo interés. Llegaron a alcanzar hasta dos tercios de los costes de producción en aquellas películas que el régimen aceptaba o impulsaba. En 1935, un 70\% de las obras de ficción producidas en Alemania disfrutaron de esas ayudas (Logenrich, 2012, p. 253). También creó un sistema de premios, asociados a una clasificación política de las películas, que facilitaba exenciones de impuestos.

El III Reich intensificó la política de cuotas a la importación de películas extranjeras, esencialmente estadounidenses, y las restricciones a su exhibición, vigentes ya durante la República de Weimar. Si en 1933 la mitad del cine exhibido en Alemania procedía de Hollywood, en 1935 no se exhibió ningún filme con ese origen y en 1941 se prohibió su importación y exhibición (Witte, 1997, p. 205).

Goebbels fue consciente del doble carácter de evasión y atribuido al cine. Por un lado, concebía el cine como «un arte que exprese su posición a través del carácter nacionalsocialista y por medio del tratamiento de problemas nacionalsocialistas» (Longerich, 2012, p. 377). Y por otro, concedía que, en el cine, «no es preciso pasarse todo el tiempo, desde temprano hasta tarde, meditando» (Longerich, 2012, p. 244).

Con el comienzo de la guerra, Goebbels frenó el cine de evasión e impuso que al menos el $50 \%$ de las películas tuviesen contenido propagandístico, aun a costa de pérdidas económicas. Pero la situación se invirtió con el devenir del conflicto y, a partir del otoño de 1941, las películas de evasión baratas desplazaron a las de propaganda y se persiguió un reparto del $80 \%-20 \%$, respectivamente, aunque el cine de propaganda no pudo cumplir su porcentaje. El público también dio la espalda a las producciones de contenido político o de carácter militar, sobre todo cuando ya escaseaban las victorias de la Wehrmacht. A partir de 1943, Goebbels perdió paulatinamente el interés por control y el papel del cine (Logenrich, 2012, p. 619).

Para satisfacer las misiones escapista y propagandística, entre 1933 y 1945 Alemania produjo más de 1.200 películas (Da Costa, 2016, p. 8) que se pueden clasificar en la siguiente tipología, a sabiendas de que no caben compartimentos estancos y que muchas obras combinan ambas intenciones.

\section{a) Películas de evasión y entretenimiento}

Su objetivo era divertir al pueblo alemán y, al mismo tiempo, mantenerlo ajeno a la crítica de las realidades sociales y políticas del régimen. En este bloque podemos distinguir: 
- Comedias y comedias musicales. Siendo ya frecuentes durante la República de Weimar, fueron especialmente utilizados para favorecer el escapismo. Un ejemplo es Viktor und Viktoria (Reinhold Schünzel, 1933).

- Melodramas. Muy del gusto de Goebbels, que siempre aspiró a producir un gran melodrama alemán y se implicó personalmente en varios como, por ejemplo, Kolberg (Veit Harlan, 1945), un costoso filme que narra el asedio y caída de la ciudad del mismo nombre bajo las tropas napoleónicas ${ }^{12}$. Pero, sin duda, el mejor ejemplo es Die grosse Liebe (Rolf Hansen, 1942), el gran éxito de público del cine del III Reich.

- Cine de montaña (Bergfilm). Este género, con una frecuente referencia a vencer dificultades y alcanzar metas, fue fortalecido durante el régimen nazi, interesado en destacar los ejemplos de superación. Son películas con tramas sencillas, rodadas en espacios naturales en el que la montaña y el paisaje alcanzan la categoría de protagonistas. Der Bergruftt! (Luis Trenker, 1938) es un buen ejemplo de estas producciones.

- Otras. Esta categoría acoge algunos filmes de temas diversos que, de manera más o menos directa, exaltan virtudes alemanas. Aquí encajan desde películas de aventuras como Münchhausen (Josef von Báky, 1943) a curiosidades como la comedia Der Mann, der Sherlock Holmes war (Karl Hartl, 1937) y también los abundantes documentales sobre naturaleza, paisajes y costumbres realizados en esta época ${ }^{13}$.

\section{b) Películas de propaganda}

Esta rúbrica agrupa un conjunto de películas que enaltecen el partido nazi y sus políticas, el espíritu alemán y las hazañas del ejército.

- Exaltación del nazismo. En este bloque se pueden considerar dos grandes tipos de películas. En primer lugar, los noticiarios semanales Die Deustche Wochenschau, que ofrecían una versión sesgada y falsa de la evolución de la guerra, y los documentales destinados a ensalzar el partido y las actividades y manifestaciones nazis, entre los que destacan Triumph des Willens y Olympia (Leni Riefenstahl, 1935 y 1938). En segundo lugar, películas como Hitlerjunge Quex (Hans Steinhoff, 1933) que enaltecen el heroísmo y el sacrificio de los miembros del partido.

- Antisemitismo y defensa de otras políticas nazis. Aunque no fueron demasiado numerosos los filmes antisemitas, sí son cualitativamente muy importantes en

12 Para su rodaje se llegó incluso a desviar tropas del frente y fue exhibida para Hitler en sus últimos días en su bunker de Berlín (Dixon y Foster, 2009, pp. 163-166 ).

${ }^{13}$ Geheimnis Tibet (Hans Lettow y Ernst Schäfer, 1943) es un caso especial. Este documental relata una expedición alemana al Tibet, financiada por Himmler. Por su contenido, y también por su montaje, esta película es considerada como un elemento de propaganda del régimen nazi. 
la historia del cine nazi. Sin duda, el más representativo es Jud Süss, la película antisemita por excelencia. Mención aparte merece el falso documental Theresienstadt (Kurt Gerron y Karel Pecený, 1944). Filmada en el campo de concentración del mismo nombre sito en Checoslovaquia, que pretendía contrarrestar las informaciones internacionales sobre los campos y mostraba a los judíos viviendo en buenas condiciones en una ciudad inexistente, creada exclusivamente para la película ${ }^{14}$. Otros documentales y películas de ficción, como Ich Klage an (Wolgang Liebeneiner, 1941), promueven políticas como la eutanasia y la ejecución de incapacitados, puestas en práctica a partir de una orden de Hitler de 1 de septiembre de 1939.

- Exaltación del espíritu alemán. Son filmes que encumbraban a políticos y otros prohombres alemanes y, simultáneamente, apostaban por la superioridad de la raza aria. Cabe destacar Die grosse Konig (Veit Harlan, 1942), dedicado a Federico II de Prusia, impulsor del estado prusiano, presentado como antecesor de Hitler. También son frecuentes filmes dedicados a científicos, artistas y músicos.

- Exaltación del ejército alemán. Se incluyen cintas de ficción y documentales que glorificaban las distintas armas del ejército alemán o describían sus campañas y sus victorias como, por ejemplo, la invasión de Polonia (Feldzug in Polen, Fritz Hippler, 1940).

- Vilipendio de las potencias rivales. Quizás el principal enemigo en la propaganda alemana fue el Reino Unido, del que se denostaba su sistema parlamentario, su impulso económico y, sobre todo, su imperio colonial, que se calificaba como asentado sobre la violencia y la opresión de los pueblos (Germanin, Max Kimmich, 1943). Tampoco olvidaron las contradicciones internas del Reino Unido, estimulando los conflictos nacionalistas en Irlanda o Escocia. La Unión Soviética fue otro de los blancos preferidos por la propaganda nazi, que se centró en la miseria, el alcoholismo, la violencia y la depravación moral del sistema con películas como Friesennot (Peter Hagen, 1935), aunque durante la vigencia del pacto Molotov-Ribbentrop la crítica se suavizó. Finalmente, tampoco los Estados Unidos se libraron de la diatriba en películas como Der verlorene Sohn (Luis Trenker, 1934), que denostaban el individualismo y la pretendida abundancia de oportunidades en el país americano.

\section{El cine en Der Adler}

\subsection{Análisis de la tipología cinematográfica en Der Adler}

En los 101 números consultados, hay referencias a ochenta y ocho películas, de las que en setenta y nueve hemos sido capaces de identificar, datar y recomponer los elementos esenciales de su ficha técnica, incluyendo director, año, principales inte-

\footnotetext{
14 También se produjeron películas con diatribas racistas contra otras razas como los latinos o los negros.
} 
grantes del reparto y alguna caracterización en cuanto a su género ${ }^{15}$. La distribución anual de las referencias cinematográficas es la siguiente: una en 1940, seis en 1941, treinta y nueveen 1942, cuarenta y dos en 1943 y doce en $1944^{16}$. Finalmente, hemos tenido la oportunidad de ver cuarenta y cuatro. El listado y la tipología de estos filmes pueden consultarse en el Anexo I.

El espacio e interés prestado por la revista no es el mismo para todas las películas. El tratamiento que se les dio fue diverso en forma e intensidad. Respetando el proceder propagandístico, la información cinematográfica es esencialmente visual, reportajes gráficos, que suelen ocupar dos páginas, cuyos textos son pies de fotos relativos al rodaje o a alguno de los fotogramas de la película. También se hallan otras referencias de carácter más publicitario, en particular, la presencia de fotos de las protagonistas femeninas (nunca, o casi nunca, un actor) de algunos de los filmes ${ }^{17}$. Finalmente, destaca también el reportaje destinado a glosar la pareja más notoria en el cine nazi formada por Veit Harlam y su esposa Kristina Söderbaum, donde se mencionan algunos de sus grandes éxitos cinematográficos ${ }^{18}$.

A la hora de analizar los contenidos de todas estas noticias cinematográficas se respetará la tipología previamente descrita para caracterizar la producción durante el régimen nazi ${ }^{19}$. Las películas mencionadas en Der Adler son, mayoritariamente, escapistas. De las ochenta y dos que se han podido estudiar en más profundidad, cincuenta y tres concuerdan plenamente con esta tipología mientras que otras veintinueve pueden adscribirse más abiertamente al cine de contenido propagandísti$\mathrm{co}^{20}$. Indudablemente, los filmes del primer grupo cumplían también una función de propaganda, bien sea porque reflejan una sociedad lujosa, feliz, incluso a veces despreocupada, bastante alejada de la realidad de Alemania, bien porque glosan la fortaleza, el sacrificio o el heroísmo cotidiano de la población. También el cambio de suerte de la guerra se deja sentir en la distribución entre las dos categorías: en 1942

15 Entre esas nueve películas defectuosamente documentadas, hemos podido identificar cinco documentales, dos de contenido bélico y tres de carácter naturalista o deportivo.

${ }^{16}$ En total, tenemos más referencias cinematográficas que películas. Evidentemente, esto es debido a que, alguna de ellas, mereció más de una mención o reportaje. Por ejemplo, hay cuatro noticias relacionadas con Die goldene Stadt.

${ }^{17}$ La imagen de la mujer en Der Adler está sujeta a un contraste que es interesante destacar. Mientras en las películas de las que se informa, y en las fotos de carteles anunciadores, se ofrece una imagen de la mujer conservadora, dependiente y tradicional, la revista también ofrece crónicas y artículos de fondo sobre mujeres más activas y decididas: aviadoras, trabajadoras en la industria alemana o participantes en otras tareas productivas.

18 Veit Harlan fue el único artista procesado como criminal de guerra siendo su película Jud Süss una de las pruebas de cargo (http://www.imdb.com/name/nm0363235/bio).

19 Aunque a efectos de este ensayo se va a mantener la distinción escapista-propagandística, podría incluirse otra categoría más vinculada al cine documental. Entre las dieciséis películas de este género descritas o mencionadas en Der Adler, encontramos un bloque de contenido bélico que, claramente, se pueden adscribir al colectivo de cine de propaganda. Pero abundan también otras de contenido, geográfico, costumbrista o naturalista que, salvando algún caso particular, se han adscrito al segmento escapista, bien podrían constituir un bloque de cine formativo y educativo.

20 De todas las películas que rastreadas en Der Adler, quince están incluidas en la lista de filmes de propaganda nazi ofrecida por Wikipedia (https://en.wikipedia.org/w/index.php?title=List_of_Nazi_ propaganda_films\&oldid=818603240). 
hallamos doce películas de propaganda y trece escapistas; en 1943 los números son siete y dieciocho, respectivamente.

En estas producciones escapistas hay un predominio de los melodramas (diecinueve), seguidos por las comedias (catorce), en ambos casos con argumentos mayoritariamente románticos. El grupo de películas clasificadas como musicales también es notable (nueve), sin olvidar que la música fue punto de referencia de un buen número de películas, ya como actividad profesional de los protagonistas, ya como biografía de alguno de los grandes compositores alemanes. Por último, en Der Adler es difícil encontrar películas de evasión asociadas con otros géneros como el thriller, el cine de aventuras. Sí se dejan notar los documentales de carácter divulgativo. Mención especial merece la película Der Schneeman (Hans Fischerkoesen, 1944), quizás la película de animación más famosa del régimen nazi ${ }^{21} \mathrm{o}$ los documentales, aunque en la muestra hay referencia a tres filmes de este tipo. No aparece ya ninguna película claramente adscrita al «cine de montaña», quizá por las fechas a las que se ciñe este estudio ${ }^{22}$.

El bloque de contenido propagandístico se nutre esencialmente de filmes en los que se exalta el genio alemán y, asociado a ello, las virtudes de la sociedad alemana y de la raza. De las veintinueve películas que se incluyen en él, catorce se destinan precisamente a ese objetivo. Destacan, en particular, las biografías de grandes prohombres alemanes: músicos (Mozart o Schumman), escultores (Andreas Schlüter), pintores (Rembrandt), inventores (Diesel) o economistas (Friedrich List), aunque en algunos casos aparecen como simples personajes de ficción. Mención aparte merecen dos filmes, Der grosse König y Kolberg, que también ofrecen el contraste de la evolución de Tercer Reich. El primero, estrenado el 3 de marzo de 1942, cuando Alemania aún dominada en los frentes de batalla, aún exalta al gran líder conductor del pueblo alemán. El segundo, estrenado el 30 de enero de 1945, puede considerarse la última producción del cine nazi y una llamada a la resistencia y al sacrificio ante la inmediata caída del régimen.

Hay espacio también para películas que menosprecian a las potencias rivales como Gran Bretaña en la ya mencionada Germanin o Titanic ((Herbert Selpin y Robert Klinger, 1943) ${ }^{23}$. Pero fue la Unión Soviética la diana de la única película (G.P.U, Kart Ritter, 1942) catalogada explícitamente como orientada hacia la crítica acerba a una nación enemiga, implicándola en campañas de terrorismo internacional.

${ }^{21}$ Goebbels, al igual que Hitler, era un enamorado de las películas de dibujos animados, aunque prohibió el cine de Disney en Alemania. Sin embargo, en 1941 creó la Deutsche Zeichentrickfilme, una compañía de cine de animación con la que pretendía competir con Disney. Hans Fischerkoesen fue uno de los creadores estrella de esta compañía (véase https://en.wikipedia.org/wiki/Hans_Fischerkoesen).

${ }^{22}$ La clasificación propuesta pretende ser ilustrativa y sistemática, pero responde también a criterios personales. Siempre que ha sido posible, se ha respetado la adscripción genérica ofrecida por imdb.com o la elegida personalmente tras visionar la película, Pero no cabe duda que hay filmes que aceptan otra adscripción. Por ejemplo, Münchhausen, a la par que comedia, es la gran película de aventuras y fantasía del III Reich y fue exportada y vista con generalidad fuera de Alemania.

${ }^{23}$ Cuando Titanic iba a ser estrenada en 1943, Goebbels la consideró derrotista y prohibió su exhibición en Alemania, aunque sí pudo verse en los países ocupados. 
Siendo Der Adler una revista oficial de la Luftwaffe, cabría esperar un buen número de menciones a películas embarcadas en la apología del ejército alemán. Así sucede en ocho películas, de las que cinco se centran en el Ejército del Aire: cuatro son obras de ficción [Kampfgeschwader Lützow (Hans Bertram, 1941), Stukas (Karl Ritter, 1941), Die Grosse Liebe y Besatzung Dora (Karl Ritter, 1943)] que tienen como protagonistas a pilotos de la Luftwaffe, y una es el documental Flieger zur See (Martin Rikli, 1938/39). De todos modos, se mantiene la impresión general de que la inclusión del cine en las páginas de Der Adler tenía como motivo principal la evasión de los lectores.

Las líneas más descarnadas de la política propagandística del III Reich, la exaltación del nazismo y las políticas raciales explícitas y, en particular, el antisemitismo, tuvieron poca cabida en las páginas de Der Adler. Apenas hay huella de una película adscrita a cada una de esas dos tipologías: Himmelhunde (Roger von Norman, 1942), que relata la vida en un campamento de las juventudes hitlerianas, y la ya referida Jud Süs. Tampoco Der Adler cargó mucho las tintas sobre este filme, pues lo comenta dentro del reportaje general sobre la vida de la pareja Harlan-Söderbaum, a la sazón guionista y director y protagonista de la película. Este posible desinterés se acomodó perfectamente a la idiosincrasia de España, un país ultracatólico donde quizás una manifestación virulenta de antisemitismo no parecía algo adecuado.

Por último, sabiendo que la edición española de Der Adler incluía reportajes propagandísticos exclusivos para el público nacional, cabía sospechar que se utilizasen sus páginas para promocionar películas españolas o, quizás con más lógica, filmes alemanes que se exhibiesen en España. Sin embargo, se ha comprobado que, en ningún caso, se empleó la versión española de la revista como un canal de publicidad en cualquiera de esos dos sentidos. La mayoría de los filmes glosados no fueron siquiera distribuidos en España. De las cincuenta y una películas alemanas incluidas en este estudio, sólo diecisiete están incluidas en el Catálogo de películas calificadas del Instituto de la Cinematografía y las Artes Audiovisuales (http://infoicaa.mecd. es/CatalogoICAA/). También se aprecia el progresivo enfriamiento de las relaciones hispano-alemanas en el ámbito cinematográfico: un tercio de las películas correspondientes a 1942 fueron catalogadas, un porcentaje que descendió al $24 \%$ en 1943. En definitiva, las noticias cinematográficas tenían como destino exclusivamente al público alemán y lo que podemos encontrarnos en la versión española es, simplemente, la traducción del papel otorgado al cine en la publicidad y propaganda del III Reich y, quizás, el reflejo de las virtudes del régimen y la sociedad alemana de cara a sus potenciales aliados.

\subsection{Un modelo económico de interpretación de la propaganda cinematográfica en períodos bélicos. El caso de Der Adler}

A continuación, vamos a presentar un modelo empírico que nos permitirá contrastar algunas hipótesis que han surgido del estudio cualitativo de la edición 
española de Der Adler y que puede añadir un enfoque cuantitativo que ayude a dilucidarlas.

Estas hipótesis, que versan sobre el carácter escapista o propagandístico del cine difundido en la revista y su relación inversa con el panorama bélico para Alemania (los reveses militares no se contrarrestan, en la economía cultural de guerra, ofreciendo películas bélicas, sino filmes de contenido escapista) son las siguientes:

1. El carácter escapista del cine difundido aumenta cuando la suerte de la contienda bélica se vuelve en contra del III Reich.

2. Las informaciones y las menciones cinematográficas en la versión española de Der Adler no se dejan influir por influencias de carácter español, tanto si hablamos de la presencia de tropas españolas combatiendo al lado de los ejércitos alemanes, como de la actividad, y la actitud, política de las instituciones alemanas en España, personalizadas, como es lógico, en el quehacer de su embajada.

3. Hay ciertos géneros que fueron particularmente utilizados para difundir la imagen escapista o para animar la propaganda.

4. El cine escapista, o al menos su manifestación en Der Adler, estuvo especialmente ligado a la actividad creativa de alguna o algunas productoras concretas, en particular, las cuatro grandes (UFA, Baviera, Terra y Tobis) que acabarían por fusionarse.

5. El régimen alemán optó por difundir más intensamente la imagen idealizada asociada a las películas de naturaleza más evasiva.

Estas hipótesis pueden ayudarnos a agrupar y a definir las variables empleadas en nuestro modelo empírico. Las películas analizadas son aquellas identificadas en las páginas de la versión española de Der Adler y su información y datos cualitativos, como por ejemplo la duración o el género, proceden de la base de datos online Internet Movie Database (IMDB), con algunas pequeñas salvedades que se apuntarán en los momentos oportunos. Vaya por delante que nuestra variable dependiente será la naturaleza o tipología de las películas difundidas en Der Adler. Esta variable, que denominaremos Tipología , tendrá un carácter binario y tomará valor uno si la película ha sido clasificada como escapista y cero si se incluye dentro del bloque considerado propagandístico. A partir de aquí, podemos describir los distintos grupos de variables explicativas ${ }^{24}$.

- Evolución de la contienda bélica. En principio, esta circunstancia se medirá a través de la variable $2 W W$, que también tiene carácter dicotómico. El fiel de la balanza de la contienda parece volverse contra Alemania a partir de octubre de 1942, cuando, como ya se ha comentado, coinciden ciertos reveses para las tropas alemanas que incluyen la derrota en El Alamein, el cerco de Stalingrado

\footnotetext{
${ }^{24}$ En el Anexo II se ofrece la definición exacta de las variables finalmente utilizadas.
} 
y los desembarcos norteamericanos en el norte de África. Por consiguiente, nuestra variable tomará valor uno para aquellas películas que aparecen en números de Der Adler editados desde el último trimestre de 1942 en adelante; en consecuencia, para todas las películas que aparecen en números anteriores a esa fecha, el valor de la variable $W W 2$ será cero ${ }^{25}$.

- Influencia española, En este bloque incluimos algunas variables que quieren recoger la posible influencia de España en los contenidos de la versión española de Der Adler. Concretamente, damos cabida a dos tipos de influencia. En primer lugar, aquella asociada con la participación de tropas españolas combatiendo al lado de los ejércitos alemanes de tierra o aire. En este caso, incluimos dos variables, DIVAZUL y ESCUAZUL, que tomarán valor 1 si la película en cuestión aparece en la revista cuando la División o la Escuadrilla Azul estaban combatiendo, respectivamente (esas unidades de voluntarios españoles estuvieron activas entre el 24 de junio de 1941 y el 23 de febrero de 1944). También hemos probado una variable única (DIVESCUAZUL) construida combinando las fechas de ambas aportaciones españolas al esfuerzo bélico del III Reich. Es decir, esta variable toma valor uno si había soldados españoles adscritos a una u otra de las unidades participando en acciones bélicas. Por otra parte, la variable STOHRER trata de tener en consideración la posible influencia de Alemania sobre la política española a través de su embajada. Primero la presencia y luego la marcha del embajador Eberhard von Stohrer, el 16 de diciembre de 1942.

- Características de la película. En este bloque incluimos varias variables que informan de ciertos rasgos cualitativos y cuantitativos de las películas.

- Duración. Por último, hemos añadido una variable más que caracteriza las películas y es su duración (IMDBTIME), con la idea implícita de que las películas escapistas son más breves o están más próximas a la duración estándar de una película de cine (90 minutos).

- Fecha de estreno. La variable AÑOESTRENO indica el año en el que se estrenó la película, según la información recogida en IMDB.

- Género. Bajo esta rúbrica se agrupan un conjunto de variables cualitativas que recogen los géneros atribuidos a las películas. En principio, se utilizan los géneros aportados por IMDB, aunque en aquellas películas que no constan en esta base de datos se acude a otras fuentes y, en unos pocos casos, a la propia impresión personal tras el visionado del filme ${ }^{26}$. Concretamente, se proponen las siguientes variables: $C O M E D Y$, para cada película tomará valor uno si IMDB le atribuye este género, y cero en caso contrario; DRAMA, para cada

${ }^{25}$ Hay películas que han aparecido en varios números de la revista. A la hora de construir esta variable, hemos tenido en cuenta la fecha de su primera aparición.

${ }^{26}$ La base de datos IMDB atribuye a cada película hasta tres posibles géneros, normalmente ordenados de manera alfabética. Hemos respetado esta variedad y, en consecuencia, habrá títulos que aparecen incorporados en más de una variable de género. 
película tomará valor uno si IMDB le atribuye este género, y cero en caso contrario; ROMANCE, para cada película tomará valor uno si IMDB le atribuye este género, y cero en caso contrario; WAROTHER, para cada película tomará valor uno si IMDB le atribuye un género distinto a comedia, drama o romance (acción, aventura, biografía, dibujos animados, crimen, documental, fantasía, historia, musical o bélica), y cero en caso contrario ${ }^{27}$.

- Productoras. Este es un conjunto de variables que recogen la productora de la película mencionada en Der Adler. En principio, se proponen las siguientes variables: $U F A$, para cada película tomará valor uno si ha sido producida por UFA, y cero en caso contrario; BAVARIA, para cada película tomará valor uno si ha sido producida por Bavaria, y cero en caso contrario; TERRA, para cada película tomará valor uno si ha sido producida por Terra, y cero en caso contrario; TOBIS, para cada película tomará valor uno si ha sido producida por Terra, y cero en caso contrario; OTRAPROD, para cada película tomará valor uno si ha sido producida por una productora distinta de cualquiera de las cuatro anteriores (esta variable actuará como categoría de referencia), y cero en caso contrario ${ }^{28}$.

- Difusión. En este grupo incluimos algunas variables que intentan recoger el grado en el que las películas aparecidas en Der Adler se difundieron a través del mundo, llegando a diversos países, en particular a España, o siendo relativamente conocidas a nivel internacional. Una vez más, la fuente fundamental para construir estas variables es IMDB. La primera de ellas, $N I M D B$, nos indica si la película en cuestión está recogida en la base de datos; tomará valor uno en caso afirmativo y valor cero en caso negativo. En segundo lugar, IMDBPLOT es una variable indirecta que recoge de un modo aproximado, la importancia atribuida a la película en la base de datos, pues toma valor uno si IMDB recoge alguna sinopsis de la trama de la película, y valor cero si no lo hace. IMDBPAIS hace recuento del número de países en los que cada película fue estrenada o ha sido, de un modo u otro, difundida. la variable IMDBESPAÑA precisa si esa película fue difundida en España, en cuyo caso tomará valor uno, o no, y entonces toma valor cero. Aún a sabiendas de que es una medida imperfecta, la popularidad de las películas tratamos de incorporarla también a través de la variable $P U N$ $T U A C I O N$, que ofrece la valoración hecha por los usuarios de IMDB, en una escala comprendida entre 0 y 10 . Somos conscientes que esta puntuación no refleja el mismo grado de aprecio y popularidad si se construye con diez o con

27 Alternativamente, y pensando en que pueden tener una mayor influencia sobre las películas de cariz propagandístico, también hemos utilizado una variable que agrupa las cintas bélicas e históricas (WARHIST), pero no ha aportado ningún resultado estadísticamente relevante.

${ }_{28}$ Hemos manejado otras especificaciones alternativas como, por ejemplo, la variable UBTT, que agrupa las cuatro grandes productoras; por consiguiente, para cada película tomará valor uno si ha sido producida por UFA, Bavaria, Terra o Tobis, y cero en caso contrario. No ha aportado ninguna mejora en los resultados de nuestro modelo. 
cien participantes. Por este motivo, añadimos la variable PUNTUADORES, que muestra el número de personas que han evaluado cada película ${ }^{29}$.

En resumen, el modelo que proponemos estimar es el siguiente:

Tipología = F [Evolución de la contienda, Influencia española, Características de la película (Duración, Género, Productora), Difusión]

Y las variables concretas utilizadas son las recogidas en el Anexo $\mathrm{II}^{30}$. Nuestra variable dependiente (NTIPOLOGIA) distingue si la película incluida en Der Adler es de naturaleza escapista o propagandística, según la clasificación elaborada en el apartado previo. Como podemos observar en el Gráfico 1, en los 4 años en los que se difundió la revista en español predominaron las películas escapistas, que suponen casi dos tercios del total (52 películas de 79, el 65,8\%).

\section{GRÁFICO 1}

DISTRIBUCIÓN DE LAS PELÍCULAS SEGÚN SU NATURALEZA

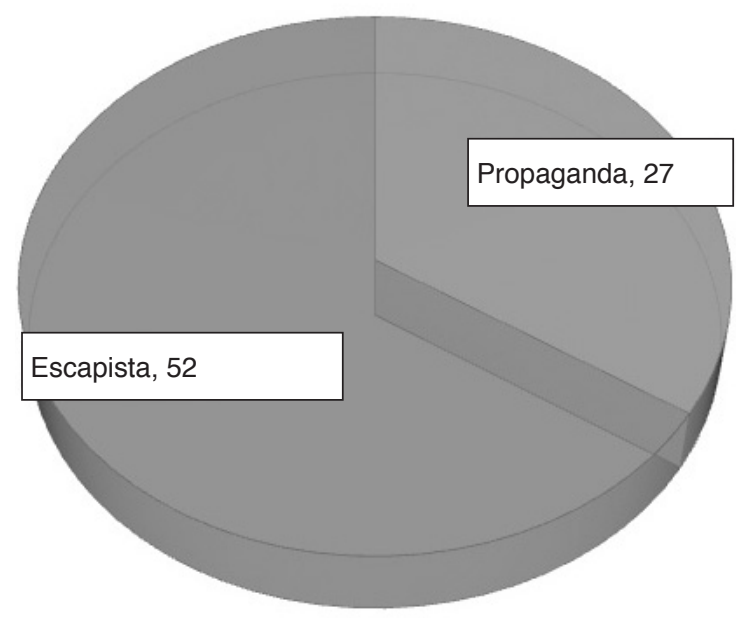

FUENTE: Elaboración propia.

${ }^{29}$ Es importante señalar que IMDB solo atribuye puntuación a aquellas películas que cuentan con un mínimo de cinco puntuadores. A efectos de la construcción de nuestra variable, hemos dado el mismo trato (missing point) a aquellas películas que no figuran en la base de datos y a aquellas que no han sido puntuadas por al menos cinco individuos.

${ }_{30}$ En el Anexo II se puede consultar la definición exacta de todas las variables y sus principales estadísticos descriptivos. 
En cuanto a las variables independientes, hemos empleado las siguientes:

- WW2, que recoge la evolución de la Segunda Guerra Mundial desde el punto de vista del III Reich.

- DIVESCUAZUL, que incorpora la presencia de voluntarios españoles encuadrados en la División Azul o la Escuadrilla Azul y combatiendo al lado de la Werhmacht o de la Luftwaffe.

- STOHRER, esta variable trata de tener en consideración la posible influencia de Alemania sobre la política española a través de su embajada. Primero la presencia y luego la marcha del embajador Eberhard von Stohrer, el 16 de diciembre de 1942.

- IMDBTIME, recoge la duración de la película según la información ofrecida por Internet Movie Data Base (IMDB).

- IMDBCOUNTRIES, indica el número de países en los que, según IMDB, la película fue estrenada o distribuida o, al menos, ofrece un título en su idioma.

- TENDRELEASE, es una tendencia temporal creada a partir de los años de estreno de las películas incluidas en nuestro estudio.

- UFA, indica si la película fue producida por la compañía UFA, la productora alemana más famosa y potente en esos años. Las demás productoras se consideran como la categoría de referencia ${ }^{31}$.

- DOCUMENTARY, indica si la película es un documental, según los géneros atribuidos en IMDB ${ }^{32}$.

- DRAMA, indica si la película es un drama, según los géneros atribuidos en IMDB.

- ROMANCE, indica si la película es romántica, según los géneros atribuidos en IMDB.

- WAROTHER, indica que la película pertenece a otro género distinto del documental, el drama, el romance o la comedia ${ }^{33}$, según los géneros atribuidos en IMDB

La estimación de una regresión logística para el modelo propuesto arroja los siguientes resultados.

En primer lugar, y como estadísticos de control de la estimación en su conjunto, hemos obtenido un $\mathrm{R}^{2}$ de Cox y Snell de 0,41 y un $\mathrm{R}^{2}$ de Nagelkerke de 0,55. Por tanto, podemos decir que nuestro modelo explica entre el 41 y el $55 \%$ de nuestra variable dependiente. Además, el modelo predice correctamente el 83,1\% de los casos, y funciona especialmente bien para predecir el comportamiento de las películas escapistas.

31 Se han probado distintas especificaciones alternativas. Por ejemplo, se agruparon las productoras más importantes (UFA, Bavaria, Terra, Tobis), dejando otras más pequeñas como categoría de referencia. Sin embargo, ninguna alternativa ofreció mejores resultados.

32 En aquellas películas a las que IMDB no atribuye ningún género se ha acudido a otras fuentes de información, incluido el visionado del filme, siempre que haya sido posible.

33 El género comedia actuará como categoría de referencia en nuestras estimaciones. 
CUADRO 1

ESTADÍSTICOS GLOBALES DEL MODELO $\left(\boldsymbol{R}^{2}\right)$

\begin{tabular}{|c|c|c|}
\hline -2 Log Verosimilitud & R cuadrado de Cox \& Snell & R cuadrad de Nagelkerke \\
\hline 60,40 & 0,41 & 0,55 \\
\hline
\end{tabular}

FUENTE: Elaboración propia.

CUADRO 2

ESTADÍSTICOS GLOBALES DEL MODELO (PORCENTAJE DE CASOS CORRECTOS PREDICHOS)

\begin{tabular}{|l|c|c|c|c|}
\hline Observado & & $\mathbf{0}$ & $\mathbf{1}$ & $\begin{array}{c}\text { Porcentaje } \\
\text { correcto }\end{array}$ \\
\hline \multirow{2}{*}{ Tipología de la película en número } & 0 & 18 & 8 & 69,23 \\
\cline { 2 - 5 } & 1 & 4 & 41 & 91,11 \\
\hline Porcentaje global & & & & 83,10 \\
\hline
\end{tabular}

FUENTE: Elaboración propia.

En cuanto al comportamiento de las variables explicativas (véase Cuadro 3), podemos comenzar diciendo que, el signo positivo y el carácter estadísticamente significativo de la variable WW2 confirman nuestra primera hipótesis: a medida que Alemania veía disminuir sus probabilidades de éxito en la contienda, aumentaba su apuesta por el cine escapista y por su promoción incluso en canales de carácter militar como Der Adler.

Nuestra segunda hipótesis, la ausencia de influencia de España, su actuación y su situación política, en los contenidos culturales y cinematográficos ofrecidos por la versión española de la revista alemana, también resulta corroborada. NI las variables asociadas con la actuación de los voluntarios españoles, ni el cambio en la actitud (y la dirección de la embajada del III Reich en Madrid) tienen ningún efecto estadísticamente significativo sobre la presencia de películas escapistas.

Un tercer bloque de hipótesis se refiere a la posible influencia de ciertas características de las películas sobre su naturaleza propagandística o escapista. En este caso, hemos encontrado resultados variados. En primer lugar, no hay diferencia entre ser una producción de UFA o de cualquiera otra productora. Este resultado tiene toda su lógica, pues la opción de las autoridades alemanas fue concentrar toda la producción cinematográfica bajo unas mismas estructura, llegando incluso a fusionar las principales productoras. En segundo lugar, la duración de la película sí ayuda a explicar su naturaleza. El signo negativo asociado a esta variable nos indica que las películas escapistas eran más contenidas en su duración, algo que parece bastante acorde con los objetivos, esencialmente de distracción, atribuibles a este tipo de cine. Finalmente, nuestra última hipótesis plantea que el cine alemán prefirió difundir sus productos de naturaleza escapista. Nuestros resultados confirman esta impresión, con el uso de 
la muestra de películas que encontraron su difusión a través de las páginas de Der Adler. El signo positivo asociado al coeficiente de la variable IMDBCOUNTRIES nos apunta una correlación positiva entre el carácter evasivo de una película y su posibilidad de acceder a mercados exteriores. Este resultado parece totalmente lógico, pues los otros países podían ver con escaso, y en muchos casos nulo o negativo, interés otras películas de contenido explícitamente propagandístico. Siempre resultaba más aceptable difundir la posición política o ideológica del régimen nazi a través de unos canales más indirectos.

\section{CUADRO 3}

RESULTADOS DE LA ESTIMACIÓN DEL MODELO LOGIT

\begin{tabular}{|l|c|c|c|c|c|c|}
\hline & Coef. & Error est. & Test Wald & g. l. & Sign. & Exp(B) \\
\hline WW2 & 2,15 & 1,14 & 3,55 & 1 & 0,059 & 8,56 \\
\hline DIVESCUAZUL & 1,22 & 1,15 & 1,12 & 1 & 0,290 & 3,40 \\
\hline STOHRER & $-0,69$ & 0,95 & 0,53 & 1 & 0,467 & 0,50 \\
\hline IMDBTIME & $-0,04$ & 0,02 & 3,52 & 1 & 0,061 & 0,96 \\
\hline IMDBCOUNTRIES & 0,23 & 0,10 & 4,76 & 1 & 0,029 & 1,25 \\
\hline TENDRELEASE & 0,21 & 0,20 & 1,07 & 1 & 0,302 & 1,23 \\
\hline UFA & 1,16 & 0,82 & 1,99 & 1 & 0,158 & 3,20 \\
\hline DOCUMENTARY & $-3,58$ & 1,92 & 3,48 & 1 & 0,062 & 0,03 \\
\hline DRAMA & $-1,67$ & 0,97 & 3,00 & 1 & 0,083 & 0,19 \\
\hline ROMANCE & 2,06 & 1,15 & 3,22 & 1 & 0,073 & 7,87 \\
\hline WAROTHER & $-1,07$ & 0,96 & 1,25 & 1 & 0,263 & 0,34 \\
\hline
\end{tabular}

FUENTE: Elaboración propia.

\section{Otros contenidos culturales}

El cine fue el arte que más páginas, fotografías y artículos acaparó. Pero Der Adler no perdió la oportunidad de utilizar otras manifestaciones artísticas, y también sociales $^{34}$, como herramientas de propaganda, siguiendo con fidelidad las ideas y consignas del Ministro Goebbels. La colección de ejemplares de Der Adler en español disponible contiene ciento treinta y siete reportajes o artículos con estos contenidos adicionales. Dejando al margen aquellos con un carácter más social, incluyendo reportajes sobre la incipiente televisión e incluso moda en plena guerra, cabe distinguir tres grandes categorías de contenidos: los relacionados con el deporte, con la cultura y con referencias a España.

\footnotetext{
${ }^{34}$ En diversas ocasiones esos reportajes se refieren a eventos de teatro, magia y humor, entre otros, ofrecidos a los soldados, bien en el frente, bien convalecientes.
} 
Los dieciocho artículos de carácter deportivo compaginan reportajes sobre eventos deportivos del ejército alemán, especialmente la aviación, con otras manifestaciones lúdico-deportivas de la población en general, en una combinación que pretende realzar las fuerzas armadas y la normalidad de la vida civil.

Las noticias culturales tienen una naturaleza más variada, aunque abundan aquellas vinculadas a las artes escénicas (treinta), las artes visuales y la literatura (veintiuna) y, muy especialmente, los reportajes de contenido musical. Incluida la ópera, hay veinticuatro reseñas entre las que predominan las destinadas a figuras musicales (directores de orquesta, solistas, intérpretes de ópera), y las que hacen referencia a festivales y conciertos. Este reparto destaca la importancia que el régimen nazi otorgó a la música clásica o, mejor dicho, a algunos de los grandes compositores y músicos alemanes ${ }^{35}$.

Aunque la versión española de Der Adler no fue un canal para promocionar el cine español, ni tan siquiera el cine alemán que se estrenaba en España, sí se aprovecharon sus páginas para destilar propaganda en favor del régimen español, tarea que se inició en 1943 y se intensificó espectacularmente en el año 1943. En 1944, cuando los voluntarios de la División Azul y la Escuadrilla Azul ya habían sido definitivamente repatriados, ya no hay ninguna noticia con un tema específicamente español ${ }^{36}$. En los 101 números disponibles se puede rastrear la presencia de treinta y cuatro reportajes de contenido español. Diecinueve ofrecen información y, sobre todo, imágenes, de los voluntarios españoles adscritos a la División Azul o la Escuadrilla Azul. Describen la vida cotidiana de los voluntarios españoles y resaltan el heroísmo de algunas de sus acciones bélicas. También hay otros cinco artículos que relatan visitas de autoridades (por ejemplo, Pilar Primo de Rivera), artistas o instituciones españolas. El resto son una miscelánea con contenidos que van desde un curso de aeromodelismo a un artículo sobre Gibraltar con una breve mención a la reivindicación española.

\section{Conclusiones}

La Economía de la cultura se ocupa normalmente de la producción y distribución de productos y servicios culturales por parte de empresas que buscan una rentabilidad. En condiciones normales de mercado, la búsqueda de prestigio o reputación mediante actividades culturales es un ingrediente secundario. Sin embargo, en momentos de conflicto bélico, conseguir la adhesión de la población del propio país o de países aliados a los objetivos del gobierno se convierte en un tema crucial, al servicio del cual se plantean diversas estrategias de propaganda cultural.

${ }^{35}$ No hay ninguna referencia grandes compositores judíos como Gustav Mahler o Arnold Schoenberg, pero sí a destacados directores o intérpretes vinculados al régimen como Wilhelm Furtwängler o Elizabeth Schwarzkopf.

${ }^{36}$ Franco dictó la orden de repatriar la División Azul el 12 de octubre de 1943 y la Escuadrilla Azul abandonó Alemania definitivamente el 23 de febrero de 1944. 
En el presente artículo se analiza un ejemplo de propaganda cultural, centrado principalmente en la propaganda cinematográfica, que fue llevado a cabo mediante la difusión en español de la revista alemana Der Adler, durante el periodo 1940-1944.

La enorme importancia que el partido nazi concedió a los nuevos medios de expresión se aprecia con la organización, ya en 1930, de un departamento cinematográfico dentro del partido y la posterior creación del Ministerio de Propaganda nada más llegar al poder, en marzo de 1933. A través de este ministerio, del que fue titular el Dr. Goebbels, se llevaba a cabo el impulso de la industria cinematográfica y, sobre todo, su orientación ideológica.

En relación con España, la propaganda alemana no se llevó a cabo de forma directa durante la primera mitad de la II Guerra Mundial (1939-1941), debido a dos factores principales. El primero de ellos fueron las victorias alemanas en los diversos frentes de batalla, que parecían hacer innecesaria una acción de propaganda para mantener la adhesión de los países simpatizantes del Eje, como era el caso de España. El segundo factor fue la enorme influencia del Agregado de Prensa de la Embajada alemana en Madrid, Hans Lazar, que controlaba y subsidiaba a la prensa española, ya de por sí germanófila, en la mayoría de las publicaciones.

Sin embargo, con el cambio de signo de las operaciones militares en todos los frentes, a partir de 1942, Alemania intensificó sus esfuerzos propagandísticos. En este contexto, se planteó el "Grosse Plan" de propaganda, que se desarrolló entre 1942 y 1944 y del cual la difusión de Der Adler fue uno de los instrumentos.

Además de su calidad gráfica, tres rasgos de la publicación deben ser destacados.

El primero es la evolución de los temas pareja a la de la contienda. Hasta 1942, hay una fuerte presencia de crónicas bélicas y militares. Desde ese año, y sobre todo a partir de febrero de 1943 con la derrota de Stalingrado y los progresos de los aliados en el frente occidental, los reportajes culturales y costumbristas van ganando cada vez más espacio.

El segundo es la fuerte presencia en sus contenidos de noticias sobre películas alemanas. Puede llamar la atención de que la mayoría de estas películas sean de temas de evasión, comedias y melodramas de trasfondo romántico y no de films de exaltación bélica, pero esta modalidad de propaganda cultural obedece a una meditada estrategia. En un momento en que la simple constatación geográfica de donde se desarrollaban las operaciones militares revelaba el retroceso de las fuerzas del Eje, se optó por difundir un cine de evasión y escapista, que distrajera a la población de los problemas diarios creados por la guerra. Visto desde una empobrecida España, la imagen de normalidad, riqueza y potencia cultural que transmitían estas películas contribuía sin duda a reforzar el prestigio de Alemania. Además, la propaganda cinematográfica se adaptó a las circunstancias de España y como ejemplo, una de las principales películas de propaganda antisemita que se produjeron en Alemania (Jude Süss) se presentó poniendo énfasis en glosar la popularidad de la pareja de actores protagonistas del film (Veit Harlam y Kristina Söderbaum). Los autores eran conscientes sin duda que el clima ultracatólico de aquella España no era igual de favorable al antisemitismo que el de Alemania. 
Y el tercer rasgo de Der Adler, en cuanto a propaganda cultural y al lado de crónicas frecuentes sobre espectáculos teatrales, musicales o circenses ofrecidos a los soldados en el frente o en centros de convalecencia, son los reportajes y películas sobre grandes compositores, ópera y musicales, que glosan normalmente la figura de algún intérprete alemán, e incluso (lo que puede parecer algo paradójico en plena Guerra Mundial) algún reportaje sobre moda.

Finalmente, hay que destacar que en la edición española de Der Adler se incluyeron también crónicas específicas dedicadas a glosar actividades culturales de los soldados de la División Azul, así como visitas a ciudades y sitios históricos, actividades deportivas y de recreo o visitas de miembros destacados del gobierno español. En 1944, con el fin de la contribución de los voluntarios españoles y la crisis que afectaba a la propia revista, desaparecen las noticias con referencia española.

\section{Referencias bibliográficas}

Alpert, M. (1996). La historia militar. En Stanley Payne y Javier Tusell (Eds.), La guerra civil. Una nueva visión del conflicto que dividió España. Madrid: Temas de Hoy.

Ciano, G. (2004). Diarios 1937-1943. Barcelona: Crítica.

Da Costa, M. (2014). Ideología y propaganda en el cine del Tercer Reich. Cuando el cine alemán se afilió al nazismo. Salamanca: Comunicación Social.

Da Costa, M. (2016). El cine del III Reich: desmontando el cine nazi en 50 películas. Madrid: Notorius.

Decreto de 4 de septiembre de 1939 ordenando la más estricta neutralidad en relación con el conflicto europeo. Boletín Oficial del Estado, 5 de septiembre de 1939, num. 248, p. 4937. Recuperado de https://fnff.es/images/carpeta_gestor/archivos/2019/09/04/Boe.4.9.1939. Decreto_neutralidad.pdf?r=7

Dixon, W., \& Gwendolyn, F. (2009). Breve historia del cine. Barcelona: Robinbook.

Elsaesser, T. (1997). Del Kaiser a la crisis de Weimar. En José Enrique Monterde y Casimiro Torreiro (Coords.), Historia General del Cine. Volumen V. Europa y Asia (1918-1930) (pp.12-59). Madrid: Cátedra.

Esteban Infantes, E (1956). La división Azul (Donde Asia empieza). Barcelona: AHR.

Garriga, R (1976). La España de Franco. Vol. 1: Las relaciones con Hitler. Vol. 2: De la División Azul al triunfo aliado, Madrid: G. del Toro.

Gomery, D., \& Pafort-Overduin, C. (2011). Movie History: A Survey. Nueva York: Editorial Routledge.

Hoare, S. (1977). Embajador ante Franco en misión especial. Madrid: Sedmay.

Hueso, Á. (1998). El cine y el siglo Xx. Barcelona: Ariel.

Hake, S. (2008). German National Cinema, 2. ${ }^{a}$ ed Abingdon: Routledge.

Irujo, J. M. (2012). La lista negra. Los espías nazis protegidos por Franco y la Iglesia. Aguilar.

Kracauer, S. (1985). De Caligari a Hitler: Una historia psicológica del cine alemán. Barcelona: Paidós.

Kreimeier, K. (1999). The UFA Story: A History of Germany's Greatest Film Company 19181945, Berkeley: U of California P. 
Larraz, J. (2006) Memorias. Madrid: Real Academia de Ciencias Morales y Políticas.

Leclerq, J. M. (n.d.). «Der Adler vino a completar la trilogía de las grandes revistas militares alemanas del periodo de la guerra». Recuperado de http://fernandez-xesta.es/PRENSA/ ARTICULOS/LOS\%20ARTICULOS.\%20Esp/-\%20DER\%20ADLER.esp.pdf

Longerich, P. (20129. Goebbels. Barcelona: RBA.

Orden de 13 de junio de 1940 sobre propaganda en España de los países beligerantes en la actual contienda. Boletín Oficial del Estado, 14 junio 1940, num. 166, pp 4087-4088. Recuperado de https://www.boe.es/datos/pdfs/BOE//1940/166/A04085-04086.pdf

Revistas de guerra: Der Adler (1 septiembre 2014). ABC.

Ros Agudo, M. (2002). La Guerra secreta de Franco. Barcelona: Crítica.

Schulze I. (1994). La propaganda alemana en España 1942-1944. Espacio, Tiempo y Forma. Serie V Historia Contemporánea, 7, pp. 371-386.

Trevor-Roper, H. (2004). Las conversaciones privadas de Hitler. Barcelona: Crítica, 2004.

Viñas, Á. (2016). Sobornos. De cómo Churchill y March compraron a los generales de Franco. Barcelona: Crítica.

Witte, K. (1997). El cine del Tercer Reich. En José Enrique Monterde y Casimiro Torreiro (Coords.), Historia General del Cine. Volumen VII. Europa y Asia (1929-1945) (pp.193230). Madrid: Cátedra. 


\section{ANEXO I \\ TIPOLOGÍA DE LAS PELÍCULAS EN DER ADLER}

\begin{tabular}{|c|c|c|c|}
\hline \multicolumn{4}{|c|}{ Evasión y entretenimiento } \\
\hline Comedias & $\begin{array}{l}\text { Musicales y comedias } \\
\text { musicales }\end{array}$ & $\begin{array}{c}\text { Dramas } \\
\text { y melodramas }\end{array}$ & $\begin{array}{c}\text { Otros (dibujos } \\
\text { animados, } \\
\text { documentales } \\
\text { naturaleza y otros) }\end{array}$ \\
\hline Traumulus (1936) & $\begin{array}{l}\text { Die Czardasfürstin } \\
\text { (1934) }\end{array}$ & $\begin{array}{l}\text { Die reise nach Tilsit } \\
\text { (1939) }\end{array}$ & Nanga Parbat (1936) \\
\hline $\begin{array}{l}\text { Scheindungsreise } \\
\text { (1938) }\end{array}$ & Immer nur-Du! (1941) & Illusion (1941 & $\begin{array}{l}\text { Schießen und Treffen } \\
(1940)\end{array}$ \\
\hline $\begin{array}{l}\text { Quax, der Bruchpilot } \\
\text { (1941) }\end{array}$ & Wiener Blut (1942) & $\begin{array}{l}\text { Die goldene Stadt } \\
\text { (1942) }\end{array}$ & $\begin{array}{l}\text { Fliegende Früchte } \\
\text { (1941) }\end{array}$ \\
\hline $\begin{array}{l}\text { Hochzeit auf Bärenhof } \\
\text { (1942) }\end{array}$ & Hab mich lieb (1942) & Zirkus Renz (1943) & $\begin{array}{l}\text { Heuzug im Allgäu } \\
(1942)\end{array}$ \\
\hline $\begin{array}{l}\text { Die Sache mit Styx } \\
\text { (1942) }\end{array}$ & $\begin{array}{l}\text { Grosstadtmelodie } \\
\text { (1943) }\end{array}$ & Immensee & $\begin{array}{l}\text { Ostpreußens Küste am } \\
\text { Meer (1943) }\end{array}$ \\
\hline $\begin{array}{l}\text { Meine Freundin Josefi- } \\
\text { ne (1942) }\end{array}$ & $\begin{array}{l}\text { Karneval der liebe } \\
(1943)\end{array}$ & Lache Bajazzo (1943) & $\begin{array}{l}\text { Der Schneemann } \\
(1944)\end{array}$ \\
\hline $\begin{array}{l}\text { Viel Lärm um Nixi } \\
\text { (1942) }\end{array}$ & $\begin{array}{l}\text { Die Zaubergeige } \\
\text { (1944) }\end{array}$ & $\begin{array}{l}\text { Die beiden Schwestern } \\
\text { (1943) }\end{array}$ & \\
\hline $\begin{array}{l}\text { Der Kleine Grenzver- } \\
\text { kehr (1943) }\end{array}$ & $\begin{array}{l}\text { Das lied der Nachtigall } \\
\text { (1944) }\end{array}$ & $\begin{array}{l}\text { Gabriele Dambrone } \\
(1943)\end{array}$ & \\
\hline Münchhausen (1943) & & $\begin{array}{l}\text { Am Ende der Welt } \\
(1943-1944)\end{array}$ & \\
\hline $\begin{array}{l}\text { Akrobat Schööön! } \\
(1943)\end{array}$ & & Späte Liebe (1943) & \\
\hline $\begin{array}{l}\text { Die kluge Marianne } \\
(1943)\end{array}$ & & $\begin{array}{l}\text { Gefährlicher Frühling } \\
\text { (1943) }\end{array}$ & \\
\hline $\begin{array}{l}\text { Herr Sandesr lebt } \\
\text { gefährlich (1944) }\end{array}$ & & $\begin{array}{l}\text { Der Majoratsherr } \\
(1943)\end{array}$ & \\
\hline \multirow[t]{6}{*}{$\begin{array}{l}\text { Die feuerzangenbowle } \\
(1945)\end{array}$} & & $\begin{array}{l}\text { Der verzauberte Tag } \\
\text { (1944) }\end{array}$ & \\
\hline & & Via Mala (1943-1945) & \\
\hline & & $\begin{array}{l}\text { Die Grosse Liebe } \\
\text { (1944) }\end{array}$ & \\
\hline & & Nora (1944) & \\
\hline & & Opfergang (1944) & \\
\hline & & Jugendliebe (1947) & \\
\hline
\end{tabular}


ANEXO I (Continuación)

TIPOLOGÍA DE LAS PELÍCULAS EN DER ADLER

\begin{tabular}{|c|c|c|c|c|c|}
\hline \multicolumn{6}{|c|}{ Propaganda } \\
\hline $\begin{array}{c}\text { Exaltación } \\
\text { del nazismo }\end{array}$ & $\begin{array}{l}\text { Antisemitismo } \\
\text { y defensa de } \\
\text { otras políticas } \\
\text { nazis }\end{array}$ & $\begin{array}{l}\text { Exaltación } \\
\text { del espíritu } \\
\text { alemán }\end{array}$ & $\begin{array}{l}\text { Exaltación } \\
\text { del ejército } \\
\text { alemán }\end{array}$ & $\begin{array}{l}\text { Vilipendio de } \\
\text { las potencias } \\
\text { rivales }\end{array}$ & $\begin{array}{l}\text { Exaltación de } \\
\text { la sociedad } \\
\text { alemana }\end{array}$ \\
\hline $\begin{array}{l}\text { Himmelhunde } \\
\text { (1942) }\end{array}$ & $\begin{array}{l}\text { Jud Süss } \\
\text { (1940) }\end{array}$ & Diesel (1942) & $\begin{array}{l}\text { Flieger zur } \\
\text { See (1939) }\end{array}$ & G.P.U.(1942) & $\begin{array}{l}\text { Ein schöner } \\
\text { Tag (1943) }\end{array}$ \\
\hline \multirow[t]{6}{*}{$\begin{array}{l}\text { Geheimnis } \\
\text { Tibet (1943) }\end{array}$} & & $\begin{array}{l}\text { Der grosse } \\
\text { König (1942) }\end{array}$ & $\begin{array}{l}\text { Kadetten } \\
(1939)\end{array}$ & $\begin{array}{l}\text { Germanin - } \\
\text { Die Geschi- } \\
\text { chte einerko- } \\
\text { lonialen Tat } \\
\text { (1943) }\end{array}$ & $\begin{array}{l}\text { Kolberg } \\
(1945)\end{array}$ \\
\hline & & $\begin{array}{l}\text { Rembrandt } \\
\text { (1942) }\end{array}$ & $\begin{array}{l}\text { Kampfges- } \\
\text { chwader Lüt- } \\
\text { zow (1941) }\end{array}$ & Titanic (1943) & \\
\hline & & $\begin{array}{l}\text { Wen Die } \\
\text { Götter Liebe } \\
(1942)\end{array}$ & Stukas (1941) & & \\
\hline & & $\begin{array}{l}\text { Geheimakte } \\
\text { W.B.1 (1942) }\end{array}$ & $\begin{array}{l}\text { Die Grosse } \\
\text { Liebe (1942) }\end{array}$ & & \\
\hline & & $\begin{array}{l}\text { Andreas } \\
\text { Schlüter } \\
\text { (1942) }\end{array}$ & $\begin{array}{l}\text { Der 5. Juni } \\
\text { (1942) }\end{array}$ & & \\
\hline & & $\begin{array}{l}\text { Zirkus Renz } \\
\text { (1943) }\end{array}$ & $\begin{array}{l}\text { Zwischen } \\
\text { Himmel und } \\
\text { Erde (1942) }\end{array}$ & & \\
\hline
\end{tabular}

FUENTE: Elaboración propia. 


\section{ANEXO II \\ MODELO ECONÓMICO DE COMPORTAMIENTO CULTURAL}

\begin{tabular}{|c|c|}
\hline Variable & Definición \\
\hline NTIPOLOGIA & $\begin{array}{l}\text { Variable dicotómica. Toma valor } 1 \text { si la película es escapista y cero si es de } \\
\text { propaganda }\end{array}$ \\
\hline $2 W W$ & $\begin{array}{l}\text { Variable dicotómica. Toma valor } 1 \text { si la película aparece en Der Adler a partir } \\
\text { de octubre de } 1942 \text { (derrota de El Alamein, desembarcos norteamericanos en } \\
\text { el norte de África, cerco de Stalingrado) y cero antes de esa fecha. }\end{array}$ \\
\hline DIVESCUAZUL & $\begin{array}{l}\text { Variable dicotómica. Toma valor } 1 \text { si la película aparece en Der Adler durante } \\
\text { el periodo en el que la División o la Escuadrilla Azul estuvieron activas (del } \\
24 \text { de junio de } 1941 \text { al } 23 \text { de febrero de 1944); y cero en otro caso }\end{array}$ \\
\hline STOHRER & $\begin{array}{l}\text { Variable dicotómica. Toma valor } 1 \text { si la película aparece en Der Adler durante } \\
\text { el mandato del embajador Stohrer (hasta el } 16 \text { de diciembre de 1942); y cero } \\
\text { en otro caso }\end{array}$ \\
\hline IMDBTIME & $\begin{array}{l}\text { Variable continua. Recoge la duración en minutos de la película, según la } \\
\text { información ofrecida por Internet Movie Data Base }\end{array}$ \\
\hline IMDBCOUNTRY & $\begin{array}{l}\text { Variable continua. Recoge el número de países en los que la película fue } \\
\text { estrenada, distribuida o, al menos, titulada en su idioma, según la información } \\
\text { ofrecida por Internet Movie Data Base }\end{array}$ \\
\hline$U F A$ & $\begin{array}{l}\text { Variable dicotómica. Toma valor } 1 \text { si la película fue producida por UFA; y } \\
\text { cero en otro caso (el resto de productoras definen la categoría de referencia) }\end{array}$ \\
\hline DOCUMENTARY & $\begin{array}{l}\text { Variable dicotómica. Toma valor } 1 \text { si la película pertenece al género } \\
\text { documental, según la información ofrecida por IMDB; y cero en otro caso (el } \\
\text { resto de productoras definen la categoría de referencia) }\end{array}$ \\
\hline$D R A M A$ & $\begin{array}{l}\text { Variable dicotómica. Toma valor } 1 \text { si la película pertenece al género drama, } \\
\text { según la información ofrecida por IMDB; y cero en otro caso (el resto de } \\
\text { productoras definen la categoría de referencia) }\end{array}$ \\
\hline ROMANCE & $\begin{array}{l}\text { Variable dicotómica. Toma valor } 1 \text { si la película pertenece al género } \\
\text { romántico, según la información ofrecida por IMDB; y cero en otro caso (el } \\
\text { resto de productoras definen la categoría de referencia) }\end{array}$ \\
\hline WAROTHER & $\begin{array}{l}\text { Variable dicotómica. Toma valor } 1 \text { si la película pertenece a cualquier otro } \\
\text { género distinto del documental, el drama, el romántico o la comedia, según } \\
\text { la información ofrecida por IMDB; y cero en otro caso (el género comedia } \\
\text { actúa como categoría de referencia) }\end{array}$ \\
\hline
\end{tabular}

FUENTE: Elaboración propia. 


\section{ESTADÍSTICOS DESCRIPTIVOS}

\begin{tabular}{|l|c|c|c|c|c|}
\hline \multicolumn{1}{|c|}{ Variable } & N & Media & $\begin{array}{c}\text { Desviación } \\
\text { estándar }\end{array}$ & Mínimo & Máximo \\
\hline NTIPOLOGIA & 79 & 0,66 & 0,48 & 0,00 & 1,00 \\
\hline 2WW & 79 & 0,70 & 0,46 & 0,00 & 1,00 \\
\hline DIVESCUAZUL & 79 & 0,91 & 0,29 & 0,00 & 1,00 \\
\hline STOHRER & 79 & 0,49 & 0,50 & 0,00 & 1,00 \\
\hline TENDERELEASE & 77 & 7,22 & 1,80 & 1,00 & 11,00 \\
\hline IMDBCOUNTRY & 73 & 5,38 & 4,67 & 0,00 & 16,00 \\
\hline UFA & 79 & 0,43 & 0,50 & 0,00 & 1,00 \\
\hline IMDBTIME & 79 & 82,66 & 31,21 & 8,00 & 118,00 \\
\hline DOCUMENTARY & 79 & 0,16 & 0,37 & 0,00 & 1,00 \\
\hline DRAMA & 79 & 0,53 & 0,50 & 0,00 & 1,00 \\
\hline ROMANCE & 79 & 0,16 & 0,37 & 0,00 & 1,00 \\
\hline WAROTHER & 79 & 0,28 & 0,45 & 0,00 & 1,00 \\
\hline
\end{tabular}

FUENTE: Elaboración propia. 